\title{
Alih Fungsi Kawasan Kampus Terpadu UII dan Pengaruhnya Terhadap Aliran Limpasan Permukaan
}

\author{
Widodo B. ${ }^{1}$; Eko Siswoyo ${ }^{2}$; dan R. Lupiyanto ${ }^{3}$ \\ 1 dan 2 Staf Pengajar Jurusan Teknik Lingkungan FTSP UII \\ ${ }^{3}$ Peneliti Pusat Studi Lingkungan UII
}

\begin{abstract}
Abstrak
Pembangunan Kampus Terpadu UII yang menempati daerah resapan primer dikhawatirkan akan menimbulkan degradasi sumberdaya air. Perkembangan kawasan terbangun diindikasikan akan meningkatkan aliran limpasan permukaan dan menurunkan pasokan airtanah. Penelitian ini dilakukan untuk mengetahui koefisien aliran limpasan permukaan (surface runoff) sesudah didirikannya Kampus Terpadu UII dengan menggunakan rumus koefisien aliran puncak (Cp) dan koefisien aliran volumetrik (Cv) serta untuk mengetahui apakah pembangunan gedung Kampus Terpadu UII memiliki dampak terhadap lingkungan, khususnya kondisi hidrologi. Penelitian menggunakan data primer dan sekunder dengan metode analisis, yaitu perhitungan matematis dan deskriptif. Hasil penelitian menunjukkan koefisien aliran puncak (Cp) pada tahun 1993 sebelum berdirinya Kampus Terpadu UII sebesar 0,3 dan pada tahun 2004 setelah berdirinya Kampus Terpadu UII sebesar 0,35, sedangkan koefisien aliran volumetrik (Cv) pada tahun 1993 sebesar 0,3 dan pada tahun 2005 sebesar 0,32. Nilai tersebut menunjukkan aliran limpasan tidak mengalami peningkatan signifikan. Artinya, pembangunan Kampus Terpadu Universitas Islam Indonesia tidak menimbulkan dampak yang sangat berbahaya terhadap lingkungan, khususnya kondisi hidrologi. Hal ini dikarenakan kawasan Kampus Terpadu UII sudah dilengkapi dengan saluran drainase yang cukup baik, sumur-sumur resapan, taman kampus dan hutan kampus.
\end{abstract}

Kata kunci: alih fungsi kawasan, aliran limpasan permukaan, Kampus Terpadu UII

\section{Latar Belakang}

Kampus Terpadu Universitas Islam Indonesia (UII) terletak di Kecamatan Ngaglik, Kabupaten Sleman, Propinsi Daerah Istimewa Yogyakarta (DIY). Lokasi ini menurut Rencana Umum Tata Ruang Daerah (RUTRD) Kabupaten Sleman berada di daerah resapan primer, sehingga pembangunan Kampus Terpadu tersebut telah banyak menimbulkan pro-kontra di kalangan masyarakat.

Keberadaan Kampus Terpadu UII membawa dampak yang sangat luas terhadap lingkungannya sebagai salah satu pemicu pertumbuhan kawasan yang sangat kuat. Sejak diresmikan pada tahun 1993, dalam waktu yang sangat singkat sudah berpengaruh pada munculnya banyak bangunan pemondokan/kos, warung makan, pelayanan jasa, rumah-rumah pribadi, dan lalu lintas di Jalan Kaliurang juga semakin padat.

Kawasan Kampus Terpadu UII berpotensi menjadi pusat pertumbuhan baru. Menurut Yunus (1981) kompleks perguruan tinggi merupakan faktor yang cukup dominan dalam mendorong proses perubahan penggunaan lahan. Pembangunan Kampus Terpadu dan perkembangan kegiatan di sekitar kampus UII membuktikan telah merubah penggunaan lahan, dari tegalan dan persawahan 
menjadi lahan terbangun. Pembangunan di kawasan Kampus Terpadu ini tidak direkomendasikan menurut RUTRD Kabupaten Sleman dikarenakan letaknya di kawasan resapan primer. Membangun di daerah resapan air berarti akan mengurangi lahan terbuka dan mengurangi volume air hujan yang meresap (infiltrasi) ke dalam tanah. Perubahan penggunaan lahan secara hidrologis juga berpengaruh pada peningkatan koefisien aliran akibat meningkatnya lahan kedap air (intervious area). Air hujan yang seharusnya sebagian terinfiltrasi ke dalam tanah berubah menjadi aliran permukaan. Kondisi ini mengkhawatirkan keseimbangan air tanah untuk Kabupaten Sleman dan Kota Yogyakarta dan kemungkinan menimbulkan banjir.

Pesatnya pertumbuhan bangunan di kawasan kampus UII sulit terkendalikan sesuai dengan ketentuan RUTRD Kabupaten Sleman yang menegaskan bahwa kepadatan bangunan maksimum di daerah kawasan resapan primer adalah 20\%. Oleh karena itu model konservasi air tanah yang diupayakan haruslah model yang cocok dengan kondisi riil yang semakin padat bangunan tersebut. Usaha konservasi air tanah yang dapat dilakukan antara lain dengan sumur resapan, sumur injeksi, pengaturan penutupan bangunan, pembuatan dam dan danau buatan, pengaturan penurapan air bawah tanah, dan penghijauan (Pemda DIY-UGM, 2001; Widodo and Prinz, 2004).

Menurut studi Pemerintah Propinsi Daerah Istimewa Yogyakarta dan Universitas Gadjah Mada (2001), kondisi air bawah tanah di kawasan Kampus Terpadu UII termasuk sensitif terhadap perubahan, baik perubahan pengambilan air (discharge) maupun pemasokan air (recharge). Air bawah tanah tersebut mutlak harus diselamatkan dari ancaman defisit oleh tingginya pengambilan air dan rendahnya suplai. Penelitian Sunjoto (1988) justru menemukan sebaliknya, yaitu pembangunan di daerah resapan air justru akan memperbesar air resapan dibandingkan dengan kondisi sebelum dibangun.

Makalah ini akan membahas imbangan air limpasan dan air resapan dari air hujan yang ada di kawasan Kampus Terpadu UII.

\section{Siklus Hidrologi}

Siklus atau daur hidrologi adalah gerakan air laut ke udara, kemudian jatuh kepermukan tanah, dan akhirnya mengalir ke laut kembali (Seyhan, 1977). Siklus hidrologi dimulai dari menguapnya air laut karena pengaruh radiasi matahari. Uap air tersebut terbawa angin menuju elevasi yang semakin tinggi dan suhu udara yang semakin menurun sehingga terkondensasi menjadi butir-butir air dan terbentuk awan hujan. Butir-butir air itu akan semakin besar dan akhirnya jatuh menjadi hujan karena gravitasi bumi. 
Sebagian air hujan yang jatuh di permukaan bumi akan menjadi aliran permukaan (surface runoff). Aliran permukaan sebagian meresap ke dalam tanah menjadi aliran bawah permukaan melalui proses infiltrasi (infiltration) dan perkolasi (percolation), selebihnya akan terkumpul di dalam jaringan alur sungai menjadi aliran sungai (river flow). Air bawah permukaan dapat kembali ke atmosfer melalui proses penguapan (evaporation) dan evapotranspirasi (evapotranspiration). Sebagian air infiltrasi akan mengalir kembali sebagai interflow ke dalam sungai atau genangan lainnya seperti waduk, danau, dan lainnya jika kondisi tanah memungkinkan (sebagai aliran air tanah/groundwater flow). Sebagian air dalam tanah juga dapat muncul kembali ke permukaan tanah sebagai air eksfiltrasi (exfiltration) dan dapat terkumpul lagi ke dalam alur sungai atau langsung menuju ke laut.

\section{Tebal Hujan}

Tebal hujan merupakan jumlah hujan yang jatuh selama satu periode kejadian hujan. Besarnya hujan yang jatuh sangat dipengaruhi oleh faktor klimatologi dan topografi daerah setempat. Untuk keperluan analisa hidrologi di suatu daerah aliran sungai (DAS) seperti pada penelitian ini, maka data curah hujan yang dibutuhkan adalah curah hujan daerah (areal rainfall) yang merupakan ratarata hujan yang jatuh di seluruh daerah aliran sungai. (Seyhan, 1977; Asdak 1995; Suripin, 2004).

\section{Lama Hujan}

Lama hujan menurut Seyhan (1977) adalah periode lamanya hujan jatuh. Lama hujan mempunyai pengaruh terhadap jumlah aliran yang terjadi. Hujan yang berlangsung lama akan mengakibatkan kapasitas infiltrasi tanah menurun, sehingga air hujan yang jatuh akan lebih banyak yang langsung menjadi aliran permukaan dan akhirnya akan dapat menyebabkan terjadinya laju pengairan atau banjir maksimum di daerah tersebut.

\section{Intensitas Hujan}

Intensitas hujan adalah jumlah hujan per satuan waktu. Nilai intensitas hujan di suatu tempat didapat dengan alat penakar hujan yang mampu mencatat besarnya volume hujan dan waktu mulai berlangsungnya hujan sampai hujan tersebut berhenti. Besarnya intensitas hujan dapat diketahui dari hasil pencatatan penakaran hujan otomatis (fluviograf) berupah sebuah lengkung penjumlahan hujan (akumulasi hujan). Data intensitas hujan tersebut umumnya dalam bentuk tabular atau grafik. Cara lain untuk menentukan besarnya intensitas curah hujan adalah dengan menggunakan teknik interval waktu yang berbeda. Data intensitas hujan dapat dimanfaatkan untuk prakiraan besarnya erosi, debit puncak (banjir), perencanaan drainase, dan bangunan air lainnya, serta prakiraan 
dampak perubahan tataguna lahan dalam skala besar terhadap perubahan karakteristik hidrologi (Asdak, 1995).

Intensitas hujan memiliki sifat hubungan dengan durasi hujan. Hujan deras (intensitas tinggi) dengan durasi lama dapat menimbulkan kerusakan-kerusakan akibat erosi ataupun akibat banjir (Asdak 1995; Suripin, 2004). Hubungan antara intensitas, lama hujan, dan frekuensi hujan biasanya dinyatakan dalam lengkung Intensitas Durasi Frekuensi (IDF). Berdasarkan data hujan jangka pendek lengkung IDF dapat dibuat salah satunya dengan Rumus Talbot (1881, dalam Asdak,1995):

$$
\begin{aligned}
& I=\frac{a}{t+b} \\
& \text { dengan: } \\
& \quad \mathrm{I}=\text { Intensitas hujan (mm/jam) } \\
& \mathrm{t}=\text { lama hujan (jam) }
\end{aligned}
$$

$\mathrm{a}$ dan $\mathrm{b}=$ konstanta yang tergantung pada lamanya hujan yang terjadi

$$
\begin{aligned}
& a=\frac{[I . t]\left[I^{2}\right]-\left[I^{2} . t\right][I]}{N\left[I^{2}\right]-[I][I]} \\
& b=\frac{[I][I . t]-N\left[I^{2} . t\right]}{N\left[I^{2}\right]-[I][I]}
\end{aligned}
$$

Intensitas hujan juga dapat dihitung dengan Rumus Manonobe apabila data hujan jangka pendek tidak tersedia dan hanya ada data hujan harian (Suripin, 2004).

$$
\begin{aligned}
& \mathbf{I}=\underset{24}{\mathbf{R}_{24}} \frac{\mathbf{2 4}}{\mathbf{t}}\left[\begin{array}{l}
\mathbf{2} / 3 \\
\text { dengan: }
\end{array}\right] \\
& \mathrm{I}=\text { Intensitas curah hujan (mm/jam) } \\
& \mathrm{t}=\text { lama hujan (jam) } \\
& \mathrm{R}_{24}=\text { curah hujan maksimum selama } 24 \text { jam }(\mathrm{mm})
\end{aligned}
$$

\section{Waktu Konsentrasi (tc)}

Waktu konsentrasi (tc) adalah waktu perjalanan yang diperlukan oleh air dari tempat yang paling jauh (hulu DAS) sampai ketitik pengamatan aliran air (outlet). Hal ini terjadi ketika tanah sepanjang kedua titik tersebut telah jenuh dan semua cekungan bumi lainnya telah terisi oleh air hujan. Waktu konsentrasi (tc) dihitung dengan persamaan matematik yang dikembangkan oleh Kirpich (1940), dalam (Asdak, 1995). 
tc $=0,0195 \frac{L^{0,77}}{S^{0,385}}$

dengan:

tc $=$ Waktu konsentrasi (menit)

$\mathrm{L}=$ panjang aliran permukaan (meter)

$\mathrm{S}=$ kemiringan rata-rata permukaan tanah $(\%)$

\section{Aliran Limpasan Permukaan}

Aliran limpasan permukaan atau air limpasan (surface runoff) adalah bagian dari curah hujan yang mengalir di atas permukaan tanah menuju ke sungai, danau dan lautan. Air limpasan berlangsung ketika jumlah curah hujan melampaui laju infiltrasi air ke dalam tanah. Faktor-faktor yang mempengaruhi laju dan volume air limpasan adalah lama waktu hujan, intensitas, dan penyebaran hujan.

Faktor-faktor yang berhubungan dengan limpasan, dapat dibagi dalam dua kelompok, yakni elemen-elemen metereologi yang diwakili oleh curah hujan dan elemen-elemen daerah pengaliran yang menyatakan sifat-sifat fisik daerah pengaliran. Faktor-faktor elemen metereologi antara lain jenis presipitasi, intensitas curah hujan, lamanya curah hujan, distribusi curah hujan, arah pergerakan curah hujan, curah hujan terdahulu dan kelembaban tanah, serta kondisi-kondisi meteorologi yang lain, seperti suhu, kecepatan angin, kelembaban relative, tekanan udara rata-rata, curah hujan tahunan dan lainnya. Selanjutnya faktor-faktor elemen daerah pengaliran antara lain penggunaan tanah (land use), daerah pengaliran, topografi, jenis tanah, faktor-faktor lain seperti karakteristik jaringan sungai-sungai, adanya daerah pengaliran yang tidak langsung, drainase buatan dan lain-lain. Faktor manusiawi juga dapat mempengaruhi, yaitu adanya sistem pengelolaan tanah dan perpindahan penduduk (Sosrodarsono and Takeda, 1986; Suripin, 2004).

Metode untuk memprakirakan besarnya air aliran puncak (peak runoff, Qp) salah satunya adalah dengan metoda rasional (U.S. Soil Conservation Service, 1986). Metoda ini relatif mudah menggunakannya dan lebih diperuntukkan pemakainannya pada DAS dengan ukuran kecil (kurang dari 300 ha). Persamaan matematis metoda rasional untuk memprakirakan besarnya air limpasan adalah sebagai berikut:

- Untuk daerah dengan luas $\leq 80 \mathrm{Ha}$

$$
Q=\frac{1}{360} \cdot C \cdot i \cdot A
$$


dengan:

$\mathrm{Q}=$ debit limpasan (L/det) dan harus diubah menjadi $\left(\mathrm{m}^{3} / \mathrm{dt}\right)$

$\mathrm{C}=$ koefisien pengaliran

$\mathrm{i}=$ rata-rata intensitas hujan yang besarnya tergantung waktu konsentrasi ( $\mathrm{mm} / \mathrm{jam})$

$\mathrm{A}=$ luas wilayah $(\mathrm{Ha})$

- Untuk daerah dengan luas $>80 \mathrm{Ha}$

$Q=\frac{1}{360} . C . C s . i . A$

360

keterangan:

$\mathrm{Cs}=$ koefisien penampungan

\section{Perhitungan Koefisien Limpasan}

Koefisien air limpasan (C) adalah bilangan yang menunjukkan perbandingan antara besarnya air limpasan terhadap besarnya curah hujan. Secara matematis, koefisien air limpasan dapat dijabarkan sebagai berikut:

$$
\text { Koefisien air limpasan }(C)=\frac{\text { air limpasan }(\mathrm{mm})}{\text { curah hujan }(\mathrm{mm})}
$$

Nilai koefisien air limpasan merupakan salah satu indikator untuk menentukan apakah suatu DAS telah mengalami gangguan (fisik). Nilai $C$ yang besar menunjukkan bahwa lebih banyak air hujan yang menjadi air limpasan sehingga ancaman terjadinya erosi dan banjir menjadi lebih besar. Angka C berkisar antara 0 sampai 1 (Asdak, 1995). Koefisien aliran dpaat dibagi menjadi dua jenis (Sosrodarsono and Takeda, 1986), yaitu koefisien volumetric dan koefisien aliran puncak.

Koefisien aliran volumetrik diperoleh dengan membagi jumlah aliran langsung dengan jumlah hujan penyebabnya. Rumus koefisien aliran volumetrik, yaitu:

$$
\mathbf{C v}=\frac{\mathbf{q}}{\mathbf{p}}
$$

dengan:

$\mathrm{Cv}$ : koefisien aliran volumetrik

$\mathrm{q}:$ aliran langsung $(\mathrm{mm})$

$\mathrm{p}:$ jumlah hujan penyebabnya (mm) 
Koefisien aliran puncak merupakan perbandingan antara besarnya puncak aliran (Qp) dengan intensitas hujan selama waktu tiba dari banjir (I) dan luas daerah pengaliran (A). Rumus koefisien aliran puncak, yaitu:

$$
\mathrm{Cp}=\frac{\mathbf{Q p}}{\mathbf{A I}}
$$

dengan:

$\mathrm{Cp}$ : koefisien aliran puncak

Qp : puncak aliran $\left(\mathrm{m}^{3} / \mathrm{det}\right)$

I : intensitas hujan rata-rata $(\mathrm{mm} / \mathrm{jam})$

A : luas daerah pengaliran $\left(\mathrm{m}^{2}\right)$

\section{Sumur Resapan}

Sumur resapan merupakan sumur atau lubang pada permukaan tanah yang dibuat untuk menampung air hujan agar dapat meresap ke dalam tanah. Sumur resapan digali dengan kedalaman di atas muka air tanah. Beberapa fungsi sumur resapan bagi kehidupan manusia adalah sebagai pengendali banjir, melindungi dan memperbaiki (konservasi) air tanah, serta menekan laju erosi. Sumur resapan merupakan upaya memperbesar resapan air hujan ke dalam tanah dan memperkecil aliran permukaan sebagai penyebab banjir.

Prinsip kerja sumur resapan adalah menyalurkan dan menampung air hujan ke dalam lubang atau sumur agar air dapat memiliki waktu tinggal di permukaan tanah lebih lama sehingga sedikit demi sedikit air dapat meresap ke dalam tanah. Fungsi sumur resapan dipengaruhi faktor iklim, kondisi air tanah, kondisi tanah, tata guna lahan, dan kondisi sosial ekonomi masyarakat. Menurut Hardjoso (dalam Sunjoto, 1988), air yang akan masuk ke dalam sumur resapan dapat diukur dengan rumus:

$$
Q=\pi \times \operatorname{Cg} \times \frac{S^{2}-H^{2}}{\operatorname{In}(r / A)}
$$

Dengan :

$\mathrm{Q}=$ Debit rembesan $\left(\mathrm{m}^{3} / \mathrm{det}\right)$

$\mathrm{Cg}=$ Koefisien pengaliran air dalam tanah $(\mathrm{m} / \mathrm{det})$

$\mathrm{S} \quad=$ Tinggi sumur resapan $(\mathrm{m})$

$\mathrm{H}=$ Tinggi muka air terhadap dasar sumur (m)

$\mathrm{r} \quad=$ Jari-jari sumur $(\mathrm{m})$

A = Jarak antar sumur (m) 
Tabel 1. Harga-harga Cg

\begin{tabular}{|l|c|}
\hline \multicolumn{1}{|c|}{ Jenis Tanah } & $C g(\mathrm{~mm} / \mathrm{det})$ \\
\hline Pasir duin (Negeri Belanda) & 0,0002 \\
Pasir dengan sedikit leem & 0,0008 \\
Pasir kali ( 0,1 sampai 0,3 mm ) & 0,0025 \\
Pasir kali ( 0,5 sampai 0,8 mm ) & 0,0088 \\
Kerikil (2,0 sampai 4,0 mm ) & 0,0300 \\
Kerikil (4,0 sampai 7,0 mm ) & 0,0351 \\
\hline
\end{tabular}

Sumber: Hardjoso (dalam Sunjoto, 1988)

\section{Metode Penelitian}

\section{Pengumpulan Data}

Data penelitian berupa data primer dan sekunder. Data primer diambil di lapangan baik dengan cara pengamatan, pengukuran, observasi maupun dengan wawancara. Data sekunder diambil secara tidak langsung, yakni berupa data instansional maupun hasil penelitian sebelumnya.

\section{Analisis Data}

Analisis data dilakukan dengan metode perhitungan matematis dan metode deskriptif. Teknik analisis adalah sebagai berikut:

\section{a. Analisa Karekteristik Hujan}

Pengukuran dan analisis karakteristik hujan antara lain:

- Curah hujan, data curah hujan diambil dari stasiun pengukur hujan otomatis.

- Tebal hujan, dengan mengukur tebal hujan pada stasiun pengukur hujan yang telah dipasang serta mengasumsikannya sebagai curah hujan wilayah.

- Lama hujan, data diambil dari stasiun pengukur hujan otomatis.

- Evapotranspirasi, data diambil dari stasiun pengukur hujan otomatis.

- Intensitas curah hujan, dihitung dengan Rumus Manonobe (Persamaan 4)

\section{b. Analisa Sumur Resapan}

Pengukuran air yang akan masuk ke dalam sumur resapan menggunakan rumus pada Persamaan 2, dengan harga $\mathrm{Cg} 0,0025 \mathrm{~mm} /$ det untuk jenis tanah pasir kali $(0,1-0,3 \mathrm{~mm})$.

\section{c. Pengukuran Debit Aliran}

Pengukuran debit aliran dapat menggunakan persamaan matematik dengan metoda rasional (Persamaan 6). 


\section{d. Perhitungan Koefisien Aliran}

- Koefisien Aliran Volumetrik

Koefisien aliran volumetrik diperoleh dengan membagi jumlah aliran langsung dengan jumlah hujan penyebabnya. Jumlah aliran langsung dengan membagi volume aliran langsung dari hidrograf aliran dengan luas DASdan jumlah hujan dapat diketahui dari pencatatan data hujan. Rumus koefisien aliran volumetrik dapat dilihat pada Persamaan 9.

- Koefisien Aliran Puncak

Koefisien aliran puncak merupakan perbandingan antara besarnya puncak aliran (Qp) dengan intensitas hujan rata-rata selama waktu tiba dari banjir (I) dan luas daerah pengaliran (A), rumus koefisien aliran puncak dapat dilihat pada Persamaan 10.

\section{Hasil Penelitian dan Pembahasan}

\section{Volume Curah Hujan}

Luas wilayah kawasan Kampus Terpadu UII pada tahun 1993 adalah 20 hektar dan pada tahun 2004 terjadi perluasan lahan menjadi 25 hektar. Volume total air hujan yang terjadi pada tahun 1993 dengan curah hujan tahunan sebesar $2.736 \mathrm{~mm}$ adalah:

$$
\begin{aligned}
\text { Vol } & =2.736 \times 10^{-3} \mathrm{~m} / \text { th } \times 200.000 \mathrm{~m}^{2} \\
& =547.200 \mathrm{~m}^{3} / \mathrm{th}
\end{aligned}
$$

Volume tersebut meningkat sejalan dengan tambahnya luas kawasan, karena keterbatasan data, curah hujan tahunan diasumsikan sama pada tahun 1993 yaitu sebesar $2.736 \mathrm{~mm}$. Volume total air hujan yang terjadi pada tahun 2004 dengan demikian sebesar:

$$
\begin{aligned}
\text { Vol } & =2.736 \times 10^{-3} \mathrm{~m} / \text { th } \times 250.000 \mathrm{~m}^{2} \\
& =684.000 \mathrm{~m}^{3} / \mathrm{th}
\end{aligned}
$$

\section{Intensitas Hujan}

Besarnya intensitas hujan dihitung dengan rumus Manonobe (dalam Subarkah, 1980), sebagaimana tersaji pada Persamaan 4. Data dasar didapatkan dari Stasiun Kemput yang terdekat dengan daerah penelitian. Rekapitukasi perhitungan intensitas hujan yang turun selama 12 tahun yaitu tahun 1993 sampai tahun 2004 dapat dilihat pada Gambar 1. 


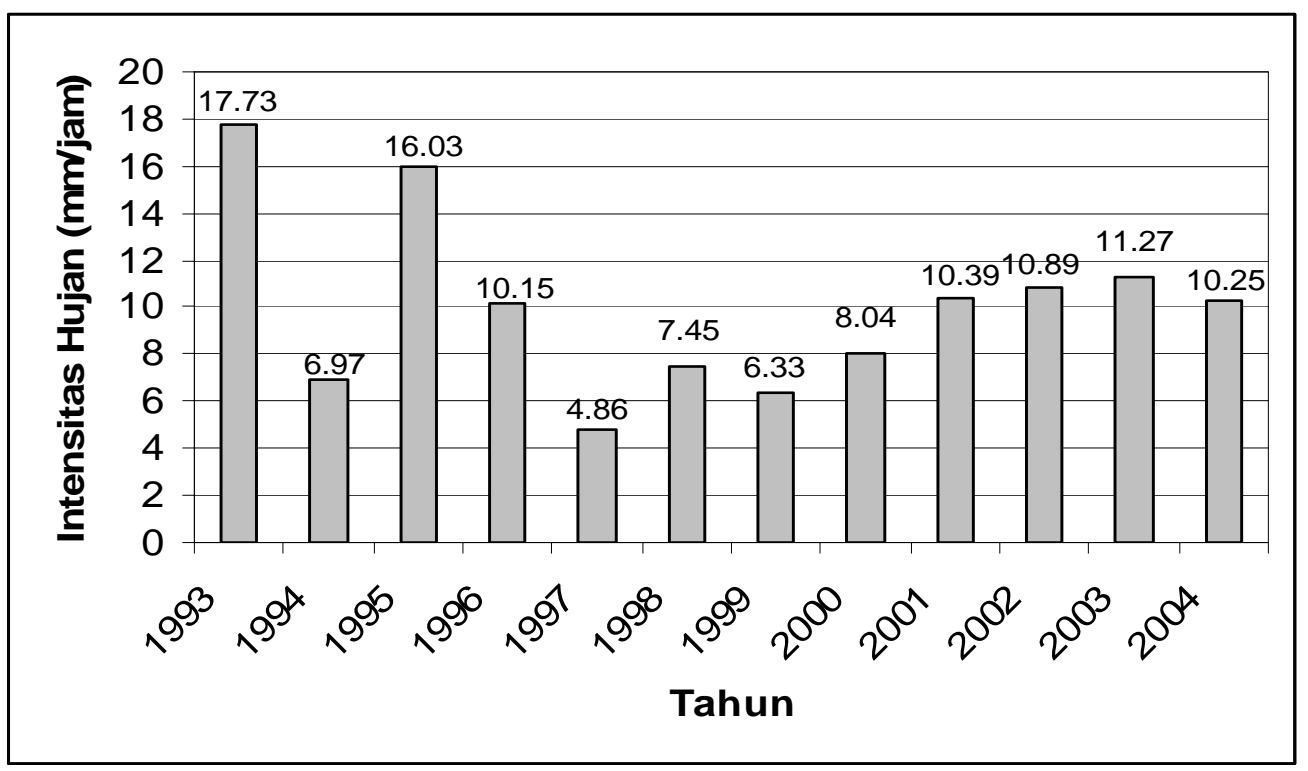

Gambar 1. Intensitas Hujan Daerah Penelitian tahun 1993-2004 (mm/jam)

\section{Debit Aliran Puncak}

Areal Kampus Terpadu UII pada tahun 1993 sebelum terjadi pembangunan 100\% masih berupa lahan hutan/tegalan/bervegetasi. Nilai koefisien aliran komposit $\left(\mathrm{C}_{\text {comp }}\right)$ dengan demikian adalah 0,3. Pada tahun 2004 pembangunan yang pesat menyebabkan perubahan pemanfaatan lahan yang drastis (Tabel 2). Masing-masing bentuk pemanfaatan lahan tersebut memiliki koefisien aliran komposit berbeda. Tabel 2 menunjukkan koefisien aliran komposit total pada tahun 2004 adalah 0,35 .

Tabel 2. Luas Pemanfaatan Lahan Kampus Terpadu UII Tahun 2004

\begin{tabular}{|c|c|c|c|c|c|}
\hline No & Jenis Pemanfaatan Lahan & Luas $\left(m^{2}\right)$ & $C$ & $C_{\text {comp }}$ & $C_{\text {comp }}$ total \\
\hline 1. & Bangunan dilengkapi sumur resapan & $74.768,00$ & 0,05 & $3.738,4$ & \multirow{6}{*}{$\begin{array}{c}86.667,31 / 250.000 \\
=0,35\end{array}$} \\
\hline 2. & $\begin{array}{l}\text { Jalan + Trotoar (paving block) + Parkir } \\
\text { Terbuka + Lapangan Basket }\end{array}$ & $46.762,16$ & 0,95 & $44.424,05$ & \\
\hline 3. & $\begin{array}{l}\text { Parkir Tertutup (beratap) + Lapangan } \\
\text { Tennis }\end{array}$ & $2.026,00$ & 0,95 & $1.924,7$ & \\
\hline 4. & Lapangan Bola & 9020,00 & 0,15 & 1.353 & \\
\hline 5. & Tanah berat dengan vegetasi & $117.423,83$ & 0,3 & $35.227,15$ & \\
\hline & Total & 250.000 & & $86.667,31$ & \\
\hline
\end{tabular}

Sumber: analisis peta; Chow dan U.S. Forest Service, 1974.

Besarnya aliran puncak limpasan permukaan yang terjadi pada tahun 1993 dan tahun 2004 dengan perhitungan menggunakan Persamaan 6 berturut-turut adalah $1.667 .340 \mathrm{~m}^{3} /$ th dan $1.362 .528 \mathrm{~m}^{3} /$ th. Perubahan penggunaan lahan di kawasan Kampus Terpadu UII pada tahun 1993-2004 membuktikan tidak terlalu berpengaruh terhadap debit puncak (Qp). Debit puncak justru mengalami penurunan sebesar 18,28\%. Penurunan tersebut dipengaruhi oleh intensitas hujan 
maksimum (Imax) dan lamanya hujan dalam tiap tahunnya. Intensitas hujan maksimum (Imax) dan lamanya hujan untuk hujan maksimum yang terjadi pada tahun 1993 lebih besar dibandingkan pada tahun 2004.

\section{Koefisien Aliran Limpasan Permukaan}

Perhitungan koefisien aliran limpasan permukaan pada penelitian ini menggunakan rumus koefisien aliran volumetric (Persamaan 9) dan koefisien aliran puncak (Persamaan 10) sebagai perbandingan. Areal Kampus Terpadu UII pada tahun 1993 sebelum terjadi pembangunan 100\% masih berupa lahan hutan / tegalan / bervegetasi. Nilai koefisien aliran volumetricnya dengan demikian adalah 0,3. Perkembangan pada tahun 2004 membutuhkan data curah hujan, evapotranspirasi, banyaknya air yang masuk ke sumur resapan, infiltrasi, dan air larian. Curah hujan rerata tahunan 2004 adalah $2,736 \mathrm{~m} / \mathrm{th}$. Evapotranspirasi yang terjadi adalah $0,9614775 \mathrm{~m} /$ th atau $240.369,375 \mathrm{~m} 3 /$ th . Berdasarkan observasi lapangan, Kampus Terpadu UII pada tahun 2004 memiliki sumur resapan dengan rincian:

- Jumlah sumur $\quad=15$ buah

- Diameter sumur $\quad=1 \mathrm{~m}$

- Kedalaman sumur $=3 \mathrm{~m}$

- Jarak antara sumur $=5 \mathrm{~m}$

- Harga $\mathrm{Cg}=0,0025 \mathrm{~mm} / \mathrm{det}$

Banyaknya air yang masuk ke dalam sumur resapan menggunakan Persamaan 11 sebesar 6047,35 $\mathrm{m}^{3} /$ th. Laju infiltrasi sebesar $0,0216 \mathrm{~m} / \mathrm{jam}$, sehingga air yang meresap adalah $215.894,53 \mathrm{~m}^{3} / \mathrm{th}$. Air larian di daerah penelitian adalah $217.688,74 \mathrm{~m}^{3} /$ th. Hasil perhitungan koefisien aliran volumetric dan koefisien aliran tersaji pada Tabel 3.

Tabel 3. Koefisien Aliran Untuk Kawasan Kampus Terpadu UII Tahun 1993 dan 2004

\begin{tabular}{|l|c|c|}
\hline \multicolumn{1}{|c|}{ Keterangan } & Tahun1993 & Tahun 2004 \\
\hline Koefisien aliran puncak & 0,3 & 0,35 \\
Koefisien aliran volumetrik & 0,3 & 0,32 \\
\hline
\end{tabular}

Nilai koefisien aliran puncak (Cp) dan koefisien aliran volumetrik (Cv) pada tahun 1993 sebesar 0,3 dengan luas area pengaliran $20 \mathrm{Ha}$. Kondisi ini berarti hujan yang jatuh di kawasan ini 30 persennya dialirkan menjadi aliran permukaan, sedangkan 70 persen sisanya hilang karena infiltrasi 
dan evapotranspirasi. Pada tahun 1993 masih dalam tahap pembangunan sehingga sebagian besar lahan di kawasan ini masih berupa lahan yang bervegetasi.

Nilai koefisien aliran puncak (Cp) untuk tahun 2004 sebesar 0,35 dengan luas lahan $25 \mathrm{Ha}$, berarti hujan yang jatuh 35 persennya menjadi aliran permukaan dan 65 persen hilang karena infiltrasi dan evapotranspirasi. Pada tahun 2004 kawasan ini sudah banyak gedung-gedung perkuliahan dan fasilitas-fasilitas penunjang untuk sarana pendidikan.

Pengaruh utama besarnya nilai koefisien aliran puncak (Cp) adalah tebal hujan, lama hujan dan intensitas hujan maksimum (Imax). Semakin besar intensitas hujan maka debit puncak yang terjadi juga semakin besar. Hal ini dikarenakan pada intensitas hujan besar air yang mengalir menjadi aliran permukaan juga besar. Hujan yang semakin besar volumenya akan memperbesar nilai aliran permukaannya. Besarnya nilai koefisien aliran volumetrik $(\mathrm{Cv})$ selanjutnya dipengaruhi oleh proses evapotranspirasi, laju infiltrasi dan banyaknya air yag masuk ke dalam sumur resapan.

Hasil perhitungan nilai koefisien aliran puncak $(\mathrm{Cp})$ dan koefisien aliran volumetrik $(\mathrm{Cv})$ tahunan pada tahun 1993 dan pada tahun 2004 tidak mengalami peningkatan yang besar, sehingga tidak terlalu berbahaya bagi lingkungan. Hal ini di karenakan pembangunan Kampus Terpadu UII sudah ditunjang oleh adanya saluran drainase yang cukup baik dan sudah dilengkapi dengan sumur-sumur resapan. Kondisi Kampus Terpadu UII pada saat ini sudah banyak terdapat taman-taman kampus dan hutan kampus, yang berfungsi untuk meresapankan air hujan ke dalam tanah (catchment area). Kenyataan tersebut menunjukkan bahwa perubahan penggunaan lahan mempunyai pengaruh yang paling besar terhadap perubahan kondisi hidrologi.

\section{Kesimpulan dan Saran}

\section{Kesimpulan}

1. Koefisien aliran puncak (Cp) pada tahun 1993 sebelum berdirinya Kampus Terpadu UII sebesar 0,3 dan pada tahun 2004 setelah berdirinya Kampus Terpadu UII sebesar 0,35.

2. Koefisien aliran volumetrik (Cv) pada tahun 1993 sebesar 0,3 dan pada tahun 2005 sebesar 0,32 .

3. Pembangunan Kampus Terpadu Universitas Islam Indonesia tidak menimbulkan dampak yang sangat berbahaya terhadap lingkungan, khususnya untuk kondisi hidrologi. Hal ini dikarenakan kawasan Kampus Terpadu UII sudah dilengkapi dengan saluran drainase yang cukup baik, 
adanya sumur-sumur resapan, taman kampus dan hutan kampus sehingga dapat meningkatkan tangkapan air hujan.

\section{Saran}

1. Penelitian tentang air di kawasan Kampus Terpadu UII sebenarnya masih dapat dikembangkan lagi, terutama berkaitan dengan masalah kualitas air maupun penelitian tentang air tanah.

2. Keberadaan Kampus Terpadu UII akan memicu pembangunan pemukiman di daerah sekitar Kampus Terpadu UII sehingga perlu penelitian lebih lanjut agar tidak ada dampak terhadap lingkungan sekitarnya.

3. Perlu adanya penelitian dengan menggunakan analisis frekuensi dengan rumus-rumus lain dan menggunakan metode periode ulang.

4. Sarana-sarana peresapan perlu ditingkatkan pengembangannya di kawasan Kampus Terpadu UII untuk mengoptimalkan fungsi resapan air.

\section{Daftar Pustaka}

Asdak, Cay. (1995). Hidrologi dan Pengelolaan Daerah Aliran Sungai Edisi II, Yogyakarta: Gadjah Mada University Press.

Chow, V.T. (1974). Handbook of Applied Hydrology, New York: McGraw-Hill Inc.

Pemda DIY-UGM. (2001). Evaluasi Potensi Air Bawah Tanah di Zona Aquifer Merapi, Propinsi Daerah Istimewa Yogyakarta. Yogyakarta: Pemda DIY-UGM.

Seyhan, Ersin. (1977). The Watershed as An Hydrologic Unit. Utrecht: Geografisch Instituut Rijkuniversiteit.

Sosrodarsono, S., dan Takeda, K. (1986). Hidrologi Untuk Pengairan. Jakarta: Pradnya Paramita.

Sunjoto. (1988). Optimasi Sumur Resapan Air Hujan Sebagai Salah Satu Usaha Pencegahan Intrusi Air Laut. Yogyakarta: Universitas Gadjah Mada.

Suripin. (2004). Pelestarian Sumberdaya Tanah dan Air. Yogyakarta: Penerbit ANDI.

U.S. Soil Conservation Service. (1986). "Urban Hydrology for Small Watersheds", Technical Release 55, 2nd ed., NTIS PB87-101580. USA: Springfield, Virginia.

Widodo. (2004). Perubahan Tata Guna Lahan dan Rencana Tata Ruang di Sebagian Wilayah DIY, Jurnal Demokrasi, Volume II, No 1, January 2004, ISSN 1693-6175.

Widodo dan Prinz. (2004). A Case of Farm Land Conversion: Land Under Threat, Research Paper of International SURED Seminar, Land and Water Resources Management. China: DAADUni Karlsruhe-Uni Oldenberg Chiang Mai.

Yunus, Hadi S. (1981). Faktor-faktor Penarik Daerah Pemekaran. Yogyakarta: Universitas Gadjah Mada. 